2016-04-04

\title{
Understanding employee turnover in humanitarian organizations
}

\author{
Dubey, $\mathrm{R}$
}

http://hdl.handle.net/10026.1/5547

10.1108/ICT-10-2015-0067

Industrial and Commercial Training

Emerald

All content in PEARL is protected by copyright law. Author manuscripts are made available in accordance with publisher policies. Please cite only the published version using the details provided on the item record or document. In the absence of an open licence (e.g. Creative Commons), permissions for further reuse of content should be sought from the publisher or author. 


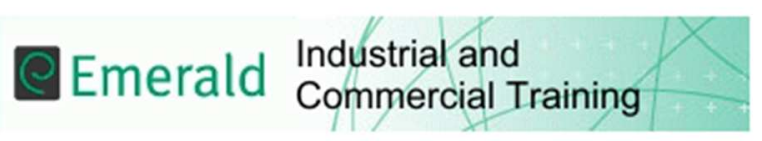

\section{Understanding employee turnover in humanitarian organizations}

\begin{tabular}{|r|l|}
\hline Journal: & Industrial and Commercial Training \\
\hline Manuscript ID & ICT-10-2015-0067.R1 \\
\hline Manuscript Type: & Article \\
\hline Keywords: & $\begin{array}{l}\text { Humanitarian Organizations, Employee Turnover, Survey Method, } \\
\text { Confirmatory Factor Analysis }\end{array}$ \\
\hline \multicolumn{2}{|l}{} \\
\hline
\end{tabular}

SCHOLARONE

Manuscripts 


\section{Understanding employee turnover in humanitarian organizations}

\section{Introduction}

In recent years disasters are becoming complex (Tomasini and Van Wassenhove, 2009).For instance, damage caused by hurricane Katrina has exceeded $\$ 125$ billion (Stecke and Kumar, 2009). Due to this complexity, challenges arise for humanitarian organizations in coordinating postdisaster activities (Yi and Ozdamar, 2007) providing relief solutions to disaster affected victims (e.g., assessing needs, moving the displaced, tending the wounded, restoring water and sewage systems) while trying to build and maintain capacity (e.g., hiring and training people, capturing lessons learned, structuring organizational processes) (Chakravarty, 2011; Goncalves, 2011).Capacity building is part of the disaster preparedness process and preparedness is a central element in reducing the impact of disasters (Jahre and Heigh, 2008; Kovács et al., 2009; Gatignon et al., 2010; Kunz et al., 2014).

In this paper we focus on the reasons of employee turnover in disaster relief activities of humanitarian organizations. Telford and Cosgrave (2007) have argued that high employee turnover has hampered the progress of disaster relief activities after 2004 Indian Ocean earthquake and tsunami. Within the field of humanitarian logistics 'employee turnover' has been identified as one of the important factor impacting the effectiveness of logistics operations (Tomasini and Van Wassenhove, 2009). And, in a recent study, Korff et al. (2015) suggested that employee turnover in humanitarian organizations has been a perennial problem. In organizational research, employee turnover, regarded as one of the consequences of work dissatisfaction has attracted considerable attention (Porter and Steers, 1973; Mitchell et al. 2001; Lee et al. 2004; Trevor and Nyberg, 2008; Allen et al. 2010; Grant et al. 2012; Parker, 2014). Therefore, apart from a few studies employee turnover and its reasons are not well understood in the context of humanitarian organizations. To address this need in the literature, the aim of this paper is 
to explore the personal reasons impacting employee turnover in humanitarian organizations. In our study we have adopted 24 variables used in Cotton and Tuttle (1986) and classified into constructs to explain turnover, and further tested our model using data gathered from humanitarian organizations.

The remainder of this paper is structured as follows. The next section is devoted to theoretical framework and research design. In the third section we discuss assumptions for statistical analyses, results of confirmatory factor analyses tests and discuss our results. Finally we conclude the paper with a critical look at our research limitations and we identify further research opportunities.

\section{Theoretical Framework}

Staff turnover and coordination problems in disaster relief teams have been cited to be the major reasons behind the failure of disaster relief initiatives (Van Wassenhove, 2006; Richardson, 2006; Altay, 2008; Tomasini and Van Wassenhove, 2009; Tatham and Kovacs, 2010).The foundation of our theoretical framework (see Figure 1) is firmly grounded in Cotton and Tuttle (1986) and Korff et al. (2015). The factors identified in these studies can provide useful insights in the debate on employee turnover (hereafter: turnover) in humanitarian organizations.

\subsection{Employee Turnover}

Turnover has received significant attention from academia and practitioners. Johnston et al. (1987) investigated the problem of turnover within a salesforce. They tested the relationship between organizational commitment, major facets of job satisfaction (pay, promotion, supervisor, work, and coworkers) and turnover among new salespeople using cross-sectional and longitudinal data, and found that there was significant difference in organizational commitment between stayers and the leavers. Allen and Griffeth (2000) have argued that job performance has significant role to play in turnover. In a later study, Allen et al. (2010) argued that despite extensive research and organizational interest in turnover, there remains a gap 
between science and practice in this area. They have provided guidelines for evidence-based retention management strategies focused on shared understanding of turnover, knowledge of cause-and-effect relationships, and the ability to adapt this knowledge. Hence, based on the work by Hom and Kinicki (2001) we argue that job dissatisfaction is the prime cause behind turnover which may be due to multiple reasons. However the reasons behind turnover may differ significantly for humanitarian organizations. The majority of research so far focuses on commercial organizations which differ significantly in terms of mission, vision, objectives and organizational structure. Although Korff et al. (2015) attempted to establish causality among the constructs leading to employee turnover in humanitarian organizations, factors affecting turnover in this realm are still not well understood.

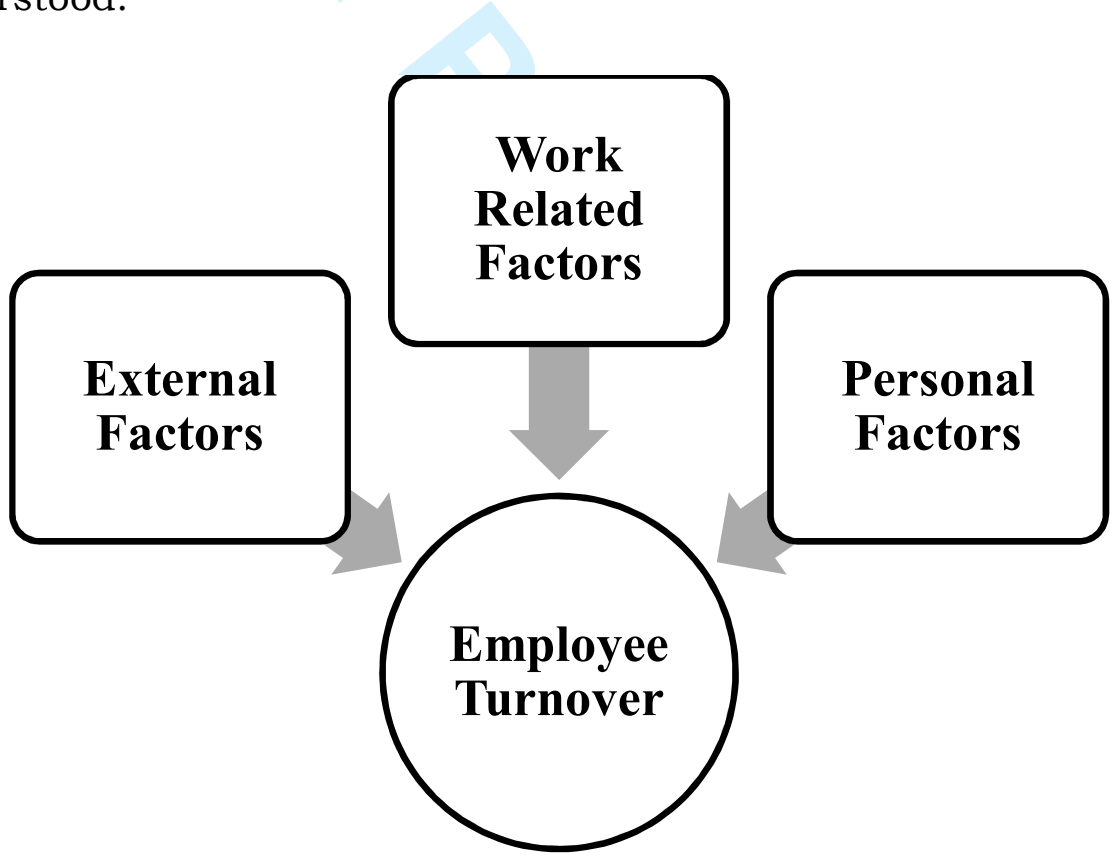

\section{Figure 1: Theoretical Framework for Employee Turnover in Humanitarian Organizations}

\subsection{Reasons behind employee turnover}

Through a meta-analytic review of organizational literature Cotton and Tuttle (1986) have identified 24 variables impacting turnover and classified them into three correlates (i.e. external, work-related, and personal characteristics). We have further reviewed the literature but the factors 
noted are subsets of the study by Cotton and Tuttle (1986)(Mitchell et al. 2001; Lee et al. 2004; Trevor and Nyberg, 2008; Allen et al. 2010; Grant et al. 2012; Parker, 2014; Korff et al. 2015). What is not understood from existing literature is that which variables and constructs have significant influence on turnover in humanitarian organizations. The study of impact of turnover on humanitarian organizations is therefore in its infancy. A study of turnover factors in the context of humanitarian organization scan offer useful insight to researchers and practitioners. Building on Cotton and Tuttle (1986) we have classified factors behind turnover into three categories as discussed below:

\subsubsection{External Factors}

External factors include 'employment perceptions', 'unemployment rate', 'accession rate', and 'union presence'. These variables are further supported by various studies (Henry, 2004; Maiers et al, 2005; Van Wassenhove, 2006; Richardson, 2006; Roth, 2012; Korff et al. 2015). Korff et al. (2015) have argued that the humanitarian workers' decision to leave the organization is guided by the attractiveness of the job (March and Simon, 1958; Cotton and Tuttle, 1986) and ease of movement (Lee and Mitchell, 1994). High turnover can be largely explained using cultural theories and nation growth theory (ibid). However in our work we are explaining how these four constructs influence employee turnover in humanitarian organizations.

\subsubsection{Work Related Factors}

Work related factors have significant role to play in employee turnover. They include 'pay', 'job performance', 'role clarity', 'task repetitiveness', 'overall job satisfaction', 'satisfaction with pay', 'satisfaction with work itself', 'satisfaction with promotional opportunities' and 'organizational commitment' (Cotton and Tuttle, 1986; Korff et al. 2015). Tatham and Kovacs (2010) attempted to explain coordination in humanitarian supply chain network and argued that how lack of trust in humanitarian supply chain network leads to poor disaster response. Their study has provided interesting insights, arguing that humanitarian organizations are hastily 
formed and the teams come from different nationalities and culture, and therefore substantial time is required to establish a common understanding. Korff et al. (2015) have further attempted to analyse the turnover problem through the lens of hastily formed organizations. Our aim, however, is to understand how these nine variables help provide better understanding into work related factors of turnover.

\subsubsection{Personal Factors}

Cotton and Tuttle (1986) have identified that personal factors play a significant role in turnover. These factors include 'age', 'tenure', 'gender', 'biographical information', 'education', 'marital status', 'number of dependents', 'aptitude and ability', 'intelligence', 'behavioural 'intention' and 'net expectations'. In our study we have found that the variables identified by Cotton and Tuttle (1986) have been used in different contexts by various researchers. Similarly, we have used these eleven variables in our current study to understand turnover in humanitarian organizations.

\section{Research Design}

This is an exploratory study, in which we are trying to understand how turnover factors identified in organizational literature play out in the humanitarian context. To accomplish this we utilized surveys. The survey instrument was developed by identifying appropriate measurements from our extensive literature review. Some modifications were made to the existing scale to make these variables more suitable to the context of humanitarian organizations. The target recipients were humanitarian organizations which have been involved in disaster relief operations in the last ten years. The questionnaire was examined first for face validity by a panel of experts who are involved in the management of the critical operations. A few changes were made based on panel suggestions. All of the exogenous constructs in the framework are operationalized as reflective constructs. 


\subsection{Data Collection}

The survey was administered to managers in humanitarian organizations who have a view of the overall operations. A sample was drawn from the members of the National Institute of Disaster Management (NIDM). India is a country frequently experiencing sudden as well as slow onset disasters.

Furthermore, a record number of NGOs have been conducting development aid work in India for a long time. Consequently, humanitarian organizations in India consist of highly experienced personnel making them string candidates for our study. Questionnaires were randomly distributes to the directors of humanitarian organizations listed in NIDM directory which may be government supported or non-governmental organizations. We initially distributed 121 questionnaires, 59 questionnaires were returned and usable for data analysis, showing an effective rate of response of $48.76 \%$. Before statistical analyses we first checked non-response bias as suggested by Armstrong and Overton (1977). We assessed non-response bias using Chisquare tests to compare the respondents against those organizations who have returned questionnaires late and found no significant differences ( $p$ $>0.05)$.

\section{Data Analysis and Results}

Our research model consists of reflective constructs. We have not considered formative constructs in this study. Our sample size is relatively small, hence partial least squares method was chosen for data analysis. In general PLS is very much suitable in explaining complex relationships (Fornell and Bookstein, 1982).

\subsection{Measurement Model}

We note that all of the reliability coefficients (SCR) are above 0.70 and each average variance extracted (AVE) is above 0.5 except for external factors (i.e. 0.37). But the factor loadings of each loaded variables are more than 0.5 (see Table 1), indicating that the measurements are reliable and the latent construct can account for at least 50 percent variance in the items. If the 
square root of the AVE (see Table 2) is greater than all the inter-construct correlations, it is evidence of sufficient discriminant validity (Fornell and Larcker, 1981). Hence we can argue that our constructs possess construct validity.

\section{Table 1: Convergent Validity}

\begin{tabular}{|c|c|c|c|c|c|c|c|c|}
\hline \multirow[t]{2}{*}{ Constructs } & Factors & Mean & $\lambda \mathrm{i}$ & $\mathrm{I} \lambda \mathrm{iI}$ & Variance & Error & SCR & AVE \\
\hline & $\begin{array}{l}\text { Employment } \\
\text { Perception }\end{array}$ & 4.46 & 0.70 & 0.70 & 0.50 & 0.50 & & \\
\hline \multirow[t]{8}{*}{ External } & $\begin{array}{c}\text { Unemployment } \\
\text { Rate }\end{array}$ & 2.00 & 0.53 & 0.53 & 0.28 & 0.72 & 0.70 & 0.37 \\
\hline & Accession Rate & 1.88 & -0.51 & 0.51 & 0.26 & 0.74 & & \\
\hline & Union Presence & 1.53 & -0.66 & 0.66 & 0.44 & 0.56 & & \\
\hline & Pay & 4.51 & 0.85 & 0.85 & 0.72 & 0.28 & & \\
\hline & Job Performance & 4.27 & 0.91 & 0.91 & 0.83 & 0.17 & & \\
\hline & Role Clarity & 4.39 & 0.89 & 0.89 & 0.79 & 0.21 & & \\
\hline & $\begin{array}{c}\text { Task } \\
\text { Repetitiveness }\end{array}$ & 4.25 & 0.90 & 0.90 & 0.81 & 0.19 & & \\
\hline & $\begin{array}{l}\text { Overall Job } \\
\text { Satisfaction }\end{array}$ & 4.17 & 0.82 & 0.82 & 0.67 & 0.33 & & \\
\hline \multirow[t]{9}{*}{ Work Related } & $\begin{array}{l}\text { Satisfaction with } \\
\text { Pay }\end{array}$ & 4.27 & 0.91 & 0.91 & 0.83 & 0.17 & 0.95 & 0.75 \\
\hline & $\begin{array}{l}\text { Satisfaction with } \\
\text { work itself }\end{array}$ & 4.69 & 0.82 & 0.82 & 0.68 & 0.32 & & \\
\hline & $\begin{array}{l}\text { Satisfaction with } \\
\text { Promotional } \\
\text { Opportunities }\end{array}$ & 4.69 & 0.82 & 0.82 & 0.68 & 0.32 & & \\
\hline & $\begin{array}{c}\text { Organizational } \\
\text { Commitment }\end{array}$ & 4.69 & 0.82 & 0.82 & 0.68 & 0.32 & & \\
\hline & Age & 4.69 & 0.53 & 0.53 & 0.28 & 0.72 & & \\
\hline & Tenure & 4.69 & 0.53 & 0.53 & 0.28 & 0.72 & & \\
\hline & Gender & 4.69 & 0.53 & 0.53 & 0.28 & 0.72 & & \\
\hline & $\begin{array}{l}\text { Biographical } \\
\text { Information }\end{array}$ & 3.59 & 0.93 & 0.93 & 0.86 & 0.14 & & \\
\hline & Education & 3.59 & 0.93 & 0.93 & 0.86 & 0.14 & & \\
\hline \multirow[t]{6}{*}{ Personal Related } & Marital Status & 3.64 & 0.94 & 0.94 & 0.89 & 0.11 & 0.94 & 0.66 \\
\hline & $\begin{array}{l}\text { Number of } \\
\text { Dependents }\end{array}$ & 3.66 & 0.94 & 0.94 & 0.89 & 0.11 & & \\
\hline & Aptitude and Ability & 3.56 & 0.89 & 0.89 & 0.79 & 0.21 & & \\
\hline & Intelligence & 3.68 & 0.87 & 0.87 & 0.76 & 0.24 & & \\
\hline & Behavioral Intention & 4.69 & $* *$ & & & & & \\
\hline & Net Expectation & 4.69 & $* *$ & & & & & \\
\hline
\end{tabular}


Table 2: Inter-Correlation Matrix

Component External Factors $\quad$ Work Related factors $\quad$ Personal Factors

\begin{tabular}{l|ccc|}
\hline External Factors & $\mathbf{0 . 6 0 8}^{*}$ & & \\
Work Related Factors & .524 & $\mathbf{0 . 8 6 6 ^ { * }}$ & .209 \\
Personal Factors & .390 & .209 & $\mathbf{0 . 8 1 2 *}^{*}$
\end{tabular}

* represents square-root of AVE

\subsection{Discussion}

Our interest in investigating the factors responsible for turnover in humanitarian organizations was triggered by the works of Tomasini and Van Wassenhove (2009), Tatham and Kovacs (2010) and Korff et al. (2015). Although the role of turnover is well established within the commercial sector, its role in humanitarian organizations has not been thoroughly investigated. As argued by Altay (2008) and Tatham and Kovacs (2010), humanitarian organizations are different from other organizations in terms of goals and objectives. Our results show that in the case of external factors we only see employment perception having a factor loading higher than 0.70. The other three variables have values less than the 0.70 threshold. That means in humanitarian organizations employment perception is a significant variable affecting turnover while union presence and accession rate having negative factor loadings are not significant factors for humanitarian organizations.

In case of work related factors, all variables are highly significant with factor loadings $(\lambda)$ greater than 0.70 indicating that work related factors do play an important role in humanitarian organizations.

Our results indicate that the personal factors including age, gender and tenure have weak factor loadings in comparison to biographical information, education, marital status, number of dependents, aptitude and ability and intelligence. Our results are in consonance with Korff et al. (2015) where 
they have noted that age and gender have no significant impacts on turnover whereas the factors like education, marital status, number of dependants, aptitude and ability, intelligence have strong impact on turnover. Lastly, we found that behavioural intentions and net expectation are not significant factors of turnover in humanitarian organizations.

For managers, our work suggests that managers wishing to reduce staff turnover in humanitarian organisations should consider the following factors. The perception of the work by the employee appears to be significant in affecting turnover, so attention should be paid to the messages that circulate within the organisation with regard to the perception of the characteristics of the work. Work-related factors are particularly important, and managers should be aware that the study indicates that changes in the work might affect turnover; this is particularly challenging in the context of a series of projects where work does tend to change. It also appears that aptitude and intelligence groupings may indicate groups where turnover could be more of a problem.

\section{Conclusions}

The current exploratory study is an attempt to understand the factors which significantly influence employee turnover in humanitarian organizations. Firmly grounded in existing literature our study adopts scales developed in the organizational science literature and further operationalizes them to suit humanitarian organizations. We found that unlike commercial organizations most of the external factors and some of the personal factors do not play a role in humanitarian organizations. Staff turnover in humanitarian organizations is mainly a function of an employee's internalization of his/her job. These internal factors not only indicate how an individual perceives his/her task environment (e.g. employment perception or job/work/ pay satisfaction) but also reflect the readiness of the individual for humanitarian work (e.g. biographical information, marital status, aptitude, intelligence etc.).These findings of our study make a significant contribution to the turnover literature because it identifies turnover factors specific to 
humanitarian organizations and offer insights to managers of humanitarian organizations.

\section{Limitations and Further Research Opportunities}

The limitations of this study are as follows: firstly, we did not test our framework using longitudinal data. Although the current study utilizes cross-sectional data, a longitudinal study may change the significance level of some factors such as 'tenure'; and secondly we tested the model using data from a developing country, India. As culture may play a role on employee's job satisfaction it may be fruitful to test this model on data obtained from developed countries, and compare/contrast the results.

The current study could be extended by studying the employee turnover problem using swift-trust theory and information-diffusion theory.

\section{References}

Allen, D.G. \& Griffeth, R.W. (2000). Job performance and turnover: A review and integrative multi-route model. Human Resource Management Review, 9(4), 525-548.

Allen, D.G., Bryant, P.C. \& Vardaman, J.M. (2010). Retaining talent: Replacing misconceptions with evidence-based strategies. The Academy of Management Perspectives, 24(2), 48-64.

Altay, N. (2008). Issues in disaster relief logistics. Large-Scale Disasters: Prediction, Control and Mitigation. Gad-el-Hak, M. (Editor), Cambridge University Press, 120-146.

Armstrong, J.S. \& Overton, T.S. (1977).Estimating nonresponse bias in mail surveys. Journal of Marketing Research, 14(3), 396-402.

Chakravarty, A.K. (2011). A contingent plan for disaster response. International Journal of Production Economics 134, 3-15.

Cotton, J.L., \& Tuttle, J.M. (1986). Employee turnover: A meta-analysis and review with implications for research. Academy of Management Review, 11(1), 55-70. 
Fornell, C., \& Larcker, D.F. (1981). Structural equation models with unobservable variables and measurement error: Algebra and statistics. Journal of Marketing Research, 18(3), 382-388.

Fornell, C., \& Bookstein, F.L. (1982). Two structural equation models: LISREL and PLS applied to consumer exit-voice theory. Journal of Marketing Research, 19(4), 440-452.

Gatignon, A., VanWassenhove, L.N. \& Charles, A. (2010). The Yogyakarta earthquake: Humanitarian relief through IFRC's decentralized supply chain. International Journal of Production Economics 126, 102-110.

Gonçalves, P. (2011). Balancing provision of relief and recovery with capacity building in humanitarian operations. Operations Management Research, 4(1-2), 39-50.

Grant, A.M. (2012). Giving time, time after time: Work design and sustained employee participation in corporate volunteering. Academy of Management Review, 37(4), 589-615.

Henry, J. (2004). Understanding HR in the Humanitarian Sector: A Baseline for Enhancing Quality in Management. Handbook 1. J. Potter \& B. Emmens (Eds.). People in Aid, London.

Hilhorst, D. \& Schmiemann, N. (2002). Humanitarian principles and organisational culture: Everyday practice in Médecins Sans Frontiéres Holland. Development in Practice, 12(3-4), 490-500.

Hom, P.W. \& Kinicki, A.J. (2001). Toward a greater understanding of how dissatisfaction drives employee turnover. Academy of Management Journal, 44(5), 975-987.

Jahre, M. \& Heigh, I. (2008). Does the current constraints in funding promote failure in humanitarian supply chains? Supply Chain Forum: an International Journal, 9, 44-54.

Johnston, M.W., Varadarajan, P.R., Futrell, C.M. \& Sager, J. (1987).The relationship between organizational commitment, job satisfaction, and turnover among new salespeople. Journal of Personal Selling \& Sales Management, 7(3), 29-38. 
Korff, V.P., Balbo, N., Mills, M., Heyse, L. \& Wittek, R. (2015).The impact of humanitarian context conditions and individual characteristics on aid worker retention. Disasters, 39(3), 522-545.

Kovács, G. \& Spens, K.M. (2009). Identifying challenges in humanitarian logistics. International Journal of Physical Distribution and Logistics Management, 39, 506-528.

Kunz, N., Reiner, G. \& Gold, S. (2014).Investing in disaster management capabilities versus pre-positioning inventory: A new approach to disaster preparedness. International Journal of Production Economics, 157, 261-272.

Lee, T.W. \& Mitchell, T.R. (1994). An alternative approach: The unfolding model of voluntary employee turnover. Academy of Management Review, 19(1), 51-89.

Lee, T.W., Mitchell, T.R., Sablynski, C.J., Burton, J.P. \& Holtom, B.C. (2004).The effects of job embeddedness on organizational citizenship, job performance, volitional absences, and voluntary turnover. Academy of Management Journal, 47(5), 711-722.

Maiers, C., Reynolds, M. \& Haselkorn, M. (2005).Challenges to effective information and communication systems in humanitarian relief organizations. In Professional Communication Conference, 2005.IPCC 2005ProceedingsInternational (pp. 82-91). IEEE.

March, J.G. \& Simon, H.A. (1958).Organizations. Wiley, New York, NY.

Mitchell, T.R., Holtom, B.C. \& Lee, T.W. (2001). How to keep your best employees: Developing an effective retention policy. The Academy of Management Executive, 15(4), 96-108.

Parker, S.K. (2014). Beyond motivation: Job and work design for development, health, ambidexterity, and more. Annual Review of Psychology, 65, 661-691.

Porter, L.W. \& Steers, R.M. (1973).Organizational, work, and personal factors in employee turnover and absenteeism. Psychological Bulletin, 80(2), 151-176. 
Richardson, F. (2006).Meeting the demand for skilled and experienced humanitarian workers. Development in Practice, 16(03-04), 334-341.

Roth, S. (2012). Professionalisation Trends and Inequality: experiences and practices in aid relationships. Third World Quarterly, 33(8), 14591474.

Stecke, K. \& Kumar, S. (2009). Sources of supply chain disruptions, factors that breed vulnerability, and mitigating strategies. Journal of Marketing Channels, 16(3), 193-226.

Tatham, P. \& Kovács, G. (2010). The application of "swift trust" to humanitarian logistics. International Journal of Production Economics, 126(1), 35-45.

Telford, J. \& Cosgrave, J. (2007). The international humanitarian system and the 2004 Indian Ocean earthquake and tsunamis. Disasters, 31(1), 128.

Tomasini, R.M. \& Van Wassenhove, L.N. (2009). From preparedness to partnerships: case study research on humanitarian logistics. International Transactions in Operational Research, 16(5), 549-559.

Trevor, C.O. \& Nyberg, A.J. (2008).Keeping your headcount when all about you are losing theirs: Downsizing, voluntary turnover rates, and the moderating role of HR practices. Academy of Management Journal, 51(2), 259-276.

Van Wassenhove, L.N. (2006). Humanitarian aid logistics: supply chain management in high gear. Journal of the Operational Research Society, 57(5), 475-489.

Yi, W. \& Ơzdamar, L. (2007).A dynamic logistics coordination model for evacuation and support in disaster response activities. European Journal of Operational Research, 179 (3), 1177-1193. 